\title{
DESIGN AND STRENGTH ANALYSIS OF A CRANE HOOK WITH A 500 KG LIFTING CAPACITY
}

\author{
Denis Molnár ${ }^{1,}$, Miroslav Blatnický1, Ján Dižo ${ }^{1}$
}

\begin{abstract}
A bridge crane is a type of crane that is designed for lifting / lowering and transferring material in the horizontal direction and is used mainly in production halls, warehouses and transship points. A part of the lifting mechanism of the bridge crane is a crane hook on which the load is suspended. Sufficient strength is required from the crane hook in order to be able to withstand high loads relatively well. The most stressed part of the crane hook is the curved inner surface. This surface is considered critical in terms of strength. The goal of this paper is to select a suitable crane hook for a single girder bridge crane with a load capacity of $500 \mathrm{~kg}$ and a strength analysis of the selected crane hook. Strength analysis is performed by two methods, first is based on analytical calculation and second is based on finite element method (FEM) performed in Ansys software. The comparison of the obtained total stresses from both methods is the part of the analysis. From the results of the FEM analysis and analytical calculation it can be stated that the selected crane hook RSN 05 P - DIN 15401 with a load capacity of $500 \mathrm{~kg}$ is suitable for the above-mentioned bridge crane. It can also be concluded that the total stress determined by the analytical calculation is lower by $9.8 \%$ compared to the stress obtained from the Ansys software.
\end{abstract}

Keywords crane hook, strength analysis, bridge crane, cross-section, Ansys, theory of strongly curved beams, finite element analysis

\section{INTRODUCTION}

Bridge cranes can be understood as mechanisms designed for lifting loads and transporting them from one place to another in the horizontal direction. It is necessary to pay attention to the relevant standards in the design process of bridge cranes and their components. Thus, for example, the design of the steel structures of the cranes is essential to carry out according to the standard STN 27 0103. This standard contains various types of loads, local stresses, tables of values of various coefficients, but also types of crane operation. One of the main parts of the lifting mechanism of the bridge crane is the crane hook (Kardile, 2017). The crane hook is a lifting component that is used to lift and grip loads. Essentially, it is a hoisting accessory designed to fit in an element of a lifting chain. Frequently utilized shapes of crane hook crosssections are circle, rectangle, triangle and trapezoid. Therefore, the crane hook needs to be designed and fabricated to provide maximum performance without breakdown (Moorthy 2020). The behaviour of a crane hook depends on its load capacity. Although the hook can withstand high loads relatively well, various deformations and failures can occur as a result of various causes. Causes include, for example, the use of incorrect bearings in the hook block or their wear, as well as the dependence on the type of fastening

\footnotetext{
${ }^{1}$ University of Žilina, Faculty of Mechanical Engineering, Department of Transport and Handling Machines, Univerzitná 8215/1, 010 26, Žilina, Slovakia

*Corresponding author, phone: + 42141513 2659, e-mail: denis.molnar@fstroj.uniza.sk
} 
of the system by which the hooks are attached to hoists or cranes. Another cause may be which materials are used in production the crane hook (Tigabey, 2018). As crane hooks are exposed to loads, the accumulation of abundant quantity of stresses can cause their breakdown in some cases. To keep down the failure of crane hook, the stress arised in it shall be investigated (Sudhakar, 2017). "Wrought iron and carbon steel are usually used in the production of crane hooks. Carbon steel is a relatively popular material to produce crane hooks." Low-alloy steels are used for heavy duty crane hooks, but the material is not the only factor in its enormous load capacity. Proper forging is very important. Forging provides better structural integrity than any other metal working process. Eliminates any defects, such as gas pockets or cavities in the hook, that can affect its long-term performance; thereby increasing its strength, toughness, load-bearing capacity and fatigue resistance (Kitaw, 2001). Parameters for crane hook like as area of cross section, material and radius of crane hook should be considered in designing process (Gopichand, 2013). So, the comparison between strength analysis of the crane hook done by mathematical calculation and done by FEA (finite element analysis) in Ansys software can show if the selected crane hook for hoisting mechanism of the single girder bridge crane with $500 \mathrm{~kg}$ load capacity is satisfying.

\section{TYPES OF CRANE HOOKS}

From the point of view of the production method, the hooks can be divided into two groups i.e., hooks made by forging and laminated hooks. These two possible ways of making hooks are the most used in practice, but there are also other possibilities of their production (Bigoš, 2012).

\subsection{Forged crane hooks}

These hooks represent a relatively widespread and most frequently used group of hooks. Based on the shape, we know single and double forged hooks. Single hooks made by forging are used for small and medium loads. Double forged hooks are mostly used for medium and higher loads. When choosing a suitable hook, it is necessary to pay attention to the requirements that the hook must meet. These requirements relate to the required load capacity, depending on the type of operation and also the strength class of the hook must be considered. The hook of one size can be used for different permissible load capacities depending on the type of operation. Single forged crane hooks with shank are quite often used in practice. Hooks of this type are the most used for cranes. There is predominantly a thread on the hook shank (Fig. 1), thanks to which the hook is attached to the hoist or to the pulley block. These hooks are used for cranes with a capacity of up to 100 tons (Cvekl, 1960, Remta 1974).

The standard STN 271908 applies to single forged hooks with the shank or it is also possible to use the DIN 15401 standard for forged hooks. DIN 15401 contains the dimensions of three types of forged hooks RSN, RF, RFN. It also lists the deviations in the surface finish, presents the field of application and purpose of these hooks and lists the strength classes of single hooks.

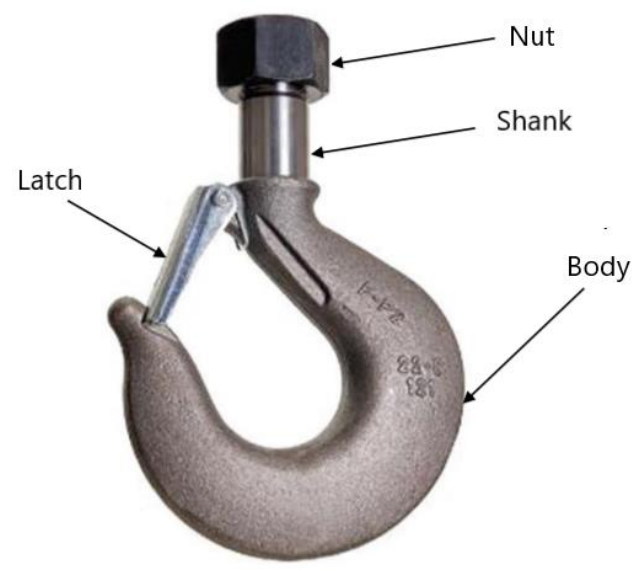

Fig. 1 Single forged crane hook (Pavlínek, 2021) 
European standards list materials and describe the properties of materials. Suitable materials used for hooks made by forging are shown in Tab. 1.

Tab. 1 Materials used for production forged crane hooks (Vítů, 2019)

\begin{tabular}{lcc}
\hline Standard of material & \multicolumn{2}{c}{ Selected materials } \\
\hline EN 10025-3 & S355N & S420N \\
EN 10222-4 & P355NH & P420NH \\
& P355QH & P420QH \\
EN 10250-2 & S355J2 & \\
EN 10086-3 & 25CrMo4+QT & 34CrNiMo+QT \\
EN 10250-3 & 34CrMo4+QT & 34CrNiMo+QT \\
& 36CrNiMo4+QT & \\
\hline
\end{tabular}

Double forged hooks are suitable and most often used for medium and higher loads. The load that can be applied to these hooks is in the range of tens to hundreds of tons, while the largest hooks in this group can reach a load capacity of more than a thousand tons. In their most common form, they occur in the form with a threaded shrank, but can also be equipped with an eye. Double forged hooks manufactured based on DIN 15402 - A are very often used in practice. Hooks made according to DIN 15402 - B are also used, while these hooks have a hole at the lower part (Ramshorn form B), which can be used to hang the load or rigging on hook if the situation it permits. The hole is made only after the hook forging process. The most commonly used are the Ramshorn hooks, which can be seen in Fig. 2 (Bigoš 2012, Cvekl 1960).

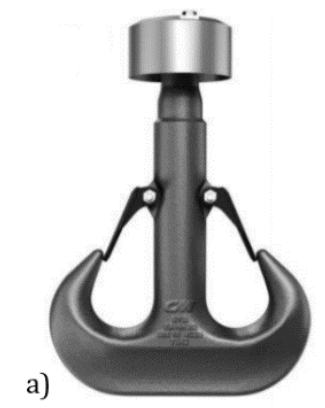

Fig. 2 Ramshorn double forged hooks a) form A, b) form B (CMCO, 2018)

\subsection{Laminated crane hooks}

Laminated hooks for cranes are a bit more complicated and consist of several steel plates that are riveted to each other (Fig. 3) to ensure higher resistance to deformation, stress and to ensure greater safety. These hooks are designed to allow the hook to continue working even if its individual parts are damaged. Laminated hooks are available as single or double laminated hooks (KItaw, 2001).

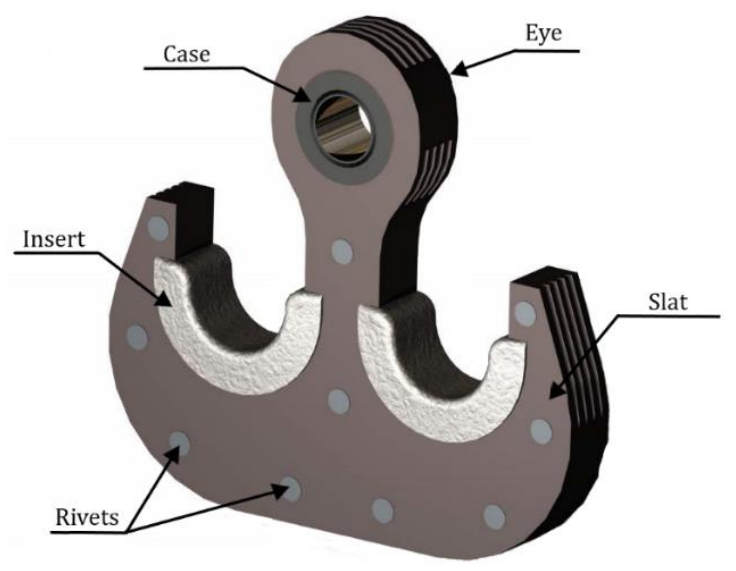

Fig. 3 Laminated crane hook (Allbiz, 2021) 
Hooks formed by slats are used mainly for hanging casting ladles, while single laminated hooks are suitable for loads up to 100 tons, double laminated hooks are used in the case of casting ladles heavier than 100 tons. The ladle pin can be hung relatively well thanks to the rectangular cross-section of the hook. These hooks are characterized by better heat resistance caused by thermal radiation and by better resistance to brittle fracture. To reduce the thermal effect on the hook, insulating inserts can be placed between the slats. These help to reduce the heat transfer between the individual slats (Bigoš, 2012; Remta, 1974).

\section{ANALYTICAL CALCULATION OF THE CRANE HOOK}

The hook is used to hang the load, but also other fastening means with the hung loads. Based on the type of production, we know a forged hook and a hook made of slats. The hook, which is produced by casting or welding, cannot be used on a crane for safety reasons (Blatnický, 2015). This paper is one part of the research of the whole transport equipment, which is the single-girder bridge crane with the load capacity of $500 \mathrm{~kg}$. Thus, the crane hook itself must have the specified load capacity. Also, based on this load capacity, the design, selection, and strength control of the crane hook is performed. The crane hook is the very important part of the crane's lifting mechanism, as it carries the entire weight of the load that is suspended on it. Therefore, it is important that the hook meets the strength requirements. The analytical calculation is performed according to the standard commonly used hook design procedure, which is based on the idealization of the cross section of the crane hook.

\subsection{Idealization of the most stressed cross-section of the crane hook}

The most stressed cross-section is the cross-section perpendicular to the vertical axis of the hook i.e., the cross-section B - B, which can be seen in Fig. 4.

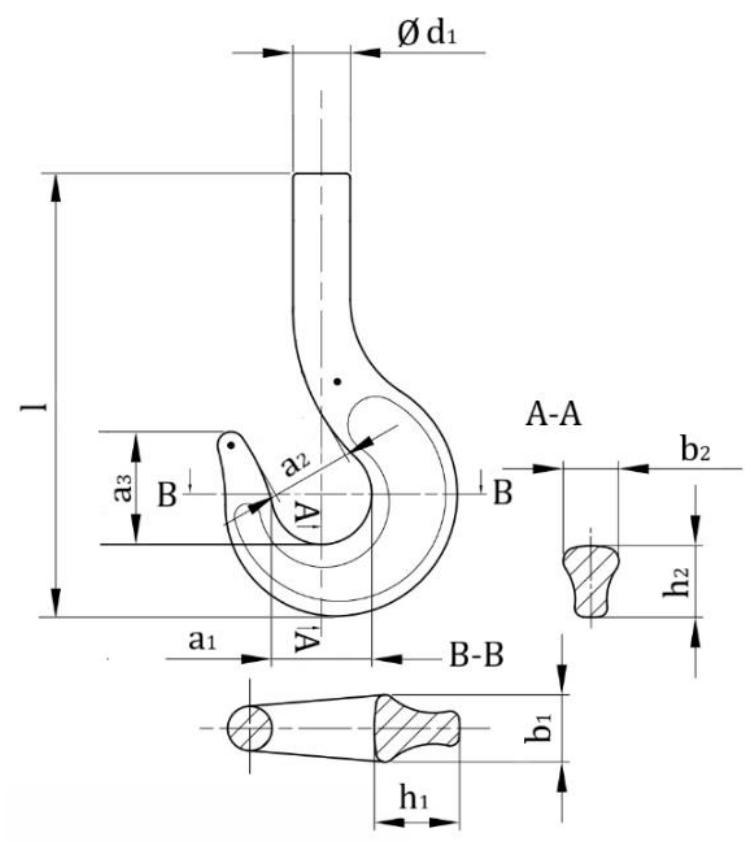

Fig. 4 Geometry of selected forged crane hook

To simplify the calculation, we can replace the shape of the cross-section with a simpler, trapezoidal shape, which is shown in Fig. 5. 


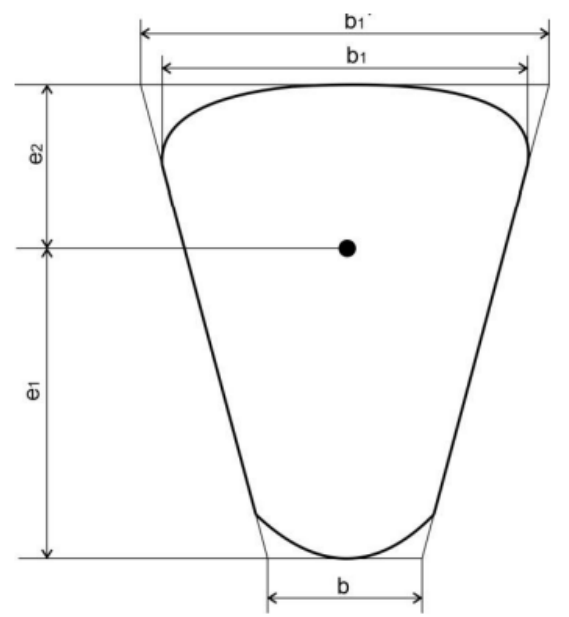

Fig. 5 Idealized real cross-section on trapezoid

The analytical calculation will be performed on the basis of the theory of strongly curved beams. Dimensions (Fig. 4) of the crane hook with a lifting capacity $Q=500 \mathrm{~kg}$ are shown in Tab. 2. Other necessary dimensions will be determined by calculation.

Tab. 2 Dimensions of selected crane hook

\begin{tabular}{cc}
\hline Dimension & Value [mm] \\
\hline $\mathrm{d}_{1}$ & 24 \\
$\mathrm{l}$ & 152 \\
$\mathrm{a}_{1}$ & 40 \\
$\mathrm{a}_{2}$ & 34 \\
$\mathrm{a}_{3}$ & 49 \\
$\mathrm{~b}_{1}$ & 29 \\
$\mathrm{~b}_{2}$ & 24 \\
$\mathrm{~h}_{1}$ & 37 \\
$\mathrm{~h}_{2}$ & 31 \\
\hline
\end{tabular}

\subsection{Calculation of crane hook dimensions}

Other necessary geometric parameters are determined from the entered data. The area of the crosssection simplified to the trapezoid $S$ is determined as follows:

$$
S=\left(\frac{b_{1}^{\prime}+b}{2}\right) \cdot h_{1}
$$

where $b_{1}{ }^{\prime}$ is longer base of trapezoid, $b$ is shorter base of trapezoid, $h_{1}$ is height of trapezoid. The value of $b_{1}{ }^{\prime}$ is $33 \mathrm{~mm}$. A value of $b$ is determined as $b=b_{1}{ }^{\prime} / 3$. Then the value of $b$ is $11 \mathrm{~mm}$. Substituting values into equation (1), the area of the cross-section is:

$$
\begin{gathered}
S=\left(\frac{33+11}{2}\right) \cdot 37 \\
S=814 \mathrm{~mm}^{2} .
\end{gathered}
$$

The position of the trapezoid center of gravity, determined by the distance from the outer $e_{1}$ and the inner $e_{2}$ wall of the hook, is calculated according to equations (3) and (4):

$$
e_{1}=\left(\frac{b+2 \cdot b_{1}^{\prime}}{b+b_{1}^{\prime}}\right) \cdot \frac{h_{1}}{3} \text {. }
$$




$$
e_{2}=\left(\frac{2 \cdot b+b_{1}^{\prime}}{b+b_{1}^{\prime}}\right) \cdot \frac{h_{1}}{3}
$$

Substituting values into equation (3) the value of $e_{1}$ is:

$$
\begin{gathered}
e_{1}=\left(\frac{11+2 \cdot 33}{11+33}\right) \cdot \frac{37}{3} \\
e_{1}=21.58 \mathrm{~mm} .
\end{gathered}
$$

Substituting values into equation (4) the value of $e_{2}$ is:

$$
\begin{gathered}
e_{2}=\left(\frac{2 \cdot 11+33}{11+33}\right) \cdot \frac{37}{3} \\
e_{2}=15.42 \mathrm{~mm} .
\end{gathered}
$$

For the purposes of further calculation, it is necessary to determine the radius of the inner end fibre $R_{1}$ and the radius of the outer end fibre $R_{2}$ (Fig. 6), which are calculated according to equations (7) and (8).

$$
\begin{gathered}
R_{1}=\frac{a_{2}}{2} . \\
R_{2}=\frac{a_{2}}{2}+h_{1} .
\end{gathered}
$$

Where $a_{2}$ is the distance between the inside of the hook end and the inside rounding of the hook shank, $h_{1}$ is height of trapezoid. Substituting values into equation (7) the value of radius $R_{1}$ is:

$$
\begin{gathered}
R_{1}=\frac{34}{2} \\
R_{1}=17 \mathrm{~mm} .
\end{gathered}
$$

Substituting values into equation (8) the value of radius $R_{2}$ is:

$$
\begin{aligned}
& R_{2}=\frac{34}{2}+37 \\
& R_{2}=54 \mathrm{~mm} .
\end{aligned}
$$

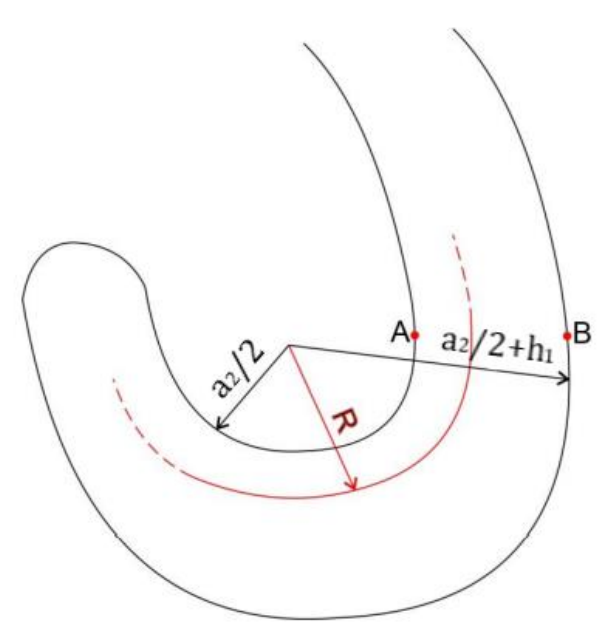

Fig. 6 Geometry of the radius R of the hook neutral fibre 
The radius of the neutral axis $R$ of the strongly curved beam of trapezoidal cross-section, which is needed to calculate the bending stresses, is calculated using equation (11).

$$
R=\frac{S}{\left(b^{\prime}{ }_{1}+R_{2} \cdot \frac{\left(b-b_{1}^{\prime}\right)}{h_{1}}\right) \cdot \ln \frac{R_{2}}{R_{1}}-\left(b-b_{1}^{\prime}\right)} .
$$

Substituting values into equation (12), the radius of the neutral axis is:

$$
\begin{gathered}
R=\frac{814}{\left(33+54 \cdot \frac{(11-33)}{37}\right) \cdot \ln \frac{54}{17}-(11-33)} \\
R=35 \mathrm{~mm} .
\end{gathered}
$$

\subsection{Calculation of acting stresses}

The tensile/compressive stress $\sigma_{t}$, which will be uniform throughout the critical cross section is first determined. The value of the tensile stress is determined from the ratio of the applied force $F$ derived from the load and the cross-sectional area of the hook $S$ :

$$
\sigma_{t}=\frac{F}{S}=\frac{Q \cdot g}{S}
$$

where $Q$ is lifting capacity of selected crane hook, $g$ is gravitational acceleration. Substituting values into equation (13) the value of tensile stress is:

$$
\begin{aligned}
\sigma_{t} & =\frac{500 \cdot 9,81}{814} \\
\sigma_{t} & =6.03 \mathrm{MPa} .
\end{aligned}
$$

The value of the bending stress will be determined for points A and B through which the boundary fibres pass. These fibres are most stressed by the bending stress. The analytical solution of bending stresses will be performed on the basis of the theory of strongly curved beams. The value of the bending stress at location $\mathrm{A} \sigma_{o A}$ is calculated according to equation (15) and the value of the bending stress at location $\mathrm{B} \sigma_{o B}$ is calculated according to equation (16).

$$
\begin{gathered}
\sigma_{O A}=\frac{M_{o} \cdot z_{A}}{\rho_{A} \cdot S_{y}} . \\
\sigma_{O B}=\frac{M_{o} \cdot z_{B}}{\rho_{B} \cdot S_{y}},
\end{gathered}
$$

where $z_{A}$ is the distance of the neutral axis from the inner end fibre, $z_{B}$ is the distance of the neutral axis from the outer end fibre, $\rho_{A}$ is curvature radius of the inner end fibre (most stressed), $\rho_{B}$ is curvature radius of the outer end fibre, $S_{y}$ is statical moment of area with respect to the neutral axis, $M_{o}$ is bending moment at the center of gravity of the cross-section. These parameters need to be calculated using the following equations.

The distance of the neutral axis from the inner end fibre $z_{A}$ is calculated as:

$$
z_{A}=R-\frac{a_{2}}{2} .
$$


Substituting values into equation (17) the $z_{A}$ is:

$$
\begin{aligned}
& z_{A}=35-\frac{34}{2} \\
& z_{A}=18 \mathrm{~mm}
\end{aligned}
$$

The distance of the neutral axis from the outer end fibre $z_{B}$ is calculated as:

$$
z_{B}=h_{1}-R+\frac{a_{2}}{2}
$$

Substituting values into equation (19) the $z_{B}$ is:

$$
\begin{gathered}
z_{B}=37-35+\frac{34}{2} \\
z_{B}=19 \mathrm{~mm} .
\end{gathered}
$$

The curvature radius of the inner end fibre (most stressed) is calculated as:

$$
\rho_{A}=\frac{a_{2}}{2} .
$$

Substituting values into equation (21) the $\rho_{A}$ is:

$$
\begin{gathered}
\rho_{A}=\frac{34}{2} \\
\rho_{A}=17 \mathrm{~mm} .
\end{gathered}
$$

The curvature radius of the outer end fibre is calculated as:

$$
\rho_{B}=\frac{a_{2}}{2}+h_{1}
$$

Substituting values into equation $(23)$ the $\rho_{B}$ is:

$$
\begin{aligned}
& \rho_{B}=\frac{34}{2}+37 \\
& \rho_{B}=54 \mathrm{~mm} .
\end{aligned}
$$

However, to calculate the statical moment of the cross-sectional area $S_{y}$, it is first necessary to determine the distance of the center of gravity of the strongly curved beam from the neutral axis $|T O|$, using equation (25):

$$
|T O|=\left(\frac{a_{2}}{2}+e_{2}-R\right)
$$

Substituting values into equation $(25)$ the $|T O|$ is:

$$
\begin{gathered}
|T O|=\left(\frac{34}{2}+15.42-35\right) \\
|T O|=|-2.58| \mathrm{mm} .
\end{gathered}
$$

Subsequently, the statical moment of the cross-sectional area $S_{y}$ is determined as: 


$$
S_{y}=S \cdot|T O|
$$

Substituting values into equation (27) the $S_{y}$ is:

$$
\begin{aligned}
& S_{y}=814 \cdot|-2.58| \\
& S_{y}=2100.12 \mathrm{~mm}^{3}
\end{aligned}
$$

The bending moment $M_{o}$ at the center of gravity of the trapezoidal cross-section, caused by the loading force $F$ is determined according to the following equation (29):

$$
M_{o}=F \cdot\left(\frac{a_{2}}{2}+e_{2}\right) \text {. }
$$

Substituting values into equation (29) the value of bending moment is:

$$
\begin{gathered}
M_{o}=4905 \cdot\left(\frac{34}{2}+15.42\right) \\
M_{o}=159020.1 \mathrm{Nmm} .
\end{gathered}
$$

Subsequently, after calculating above parameters, the bending stress at location A $\sigma_{o A}$ can be calculated using equation (15):

$$
\begin{aligned}
\sigma_{O A} & =\frac{159020.1 \cdot 18}{17 \cdot 2100.12} \\
\sigma_{O A} & =80.17 \mathrm{MPa} .
\end{aligned}
$$

Also, after substituting values into equation (16) the value of bending stress at location $\mathrm{B} \sigma_{o B}$ is:

$$
\begin{aligned}
\sigma_{O B} & =\frac{159020.1 \cdot 19}{54 \cdot 2100.12} \\
\sigma_{O B} & =26.64 \mathrm{MPa} .
\end{aligned}
$$

From the calculated values it is clear that the fibre passing through the point $A$ is the most stressed for bending. Therefore, only the point A will be considered to determine the total stress. Then the total stress in the location $\mathrm{A} \sigma_{A}$ is calculated as:

$$
\sigma_{A}=\sigma_{t}+\sigma_{O A}
$$

where $\sigma_{t}$ is tensile/compressive stress, $\sigma_{o A}$ is bending stress in location A. Substituting values into equation (33) the $\sigma_{A}$ is:

$$
\begin{gathered}
\sigma_{A}=6.03+80.17 \\
\sigma_{A}=86.2 \mathrm{MPa} .
\end{gathered}
$$

By idealizing the cross-sectional shape of the crane hook on the trapezoid, the area increased and thus the stresses decreased. Based on these facts, the real result will be about $25-30 \%$ higher. Therefore, to obtain the real total stress $\sigma_{A r}$, the correction coefficient $k=0.75(-)$, which takes into account the above fact will be used. Then the real total stress $\sigma_{A r}$ is calculated as: 


$$
\sigma_{A r}=\frac{\sigma_{A}}{k}
$$

Substituting values into equation (35), the value of $\sigma_{A r}$ is:

$$
\begin{gathered}
\sigma_{A r}=\frac{86.2}{0.75} \\
\sigma_{A r}=114.93 \mathrm{MPa} .
\end{gathered}
$$

Thus, the real stress in the most stressed cross-section is $\sigma_{A r}=114.93 \mathrm{MPa}$.

The following condition (37) must be met for the crane hook to be suitable. This condition is based on the fact that the real total stress $\sigma_{A \mathrm{r}}$ in the most stressed cross-section must be less than the permissible stress $\sigma_{\text {per }}$

$$
\sigma_{A r} \leq \sigma_{p e r}
$$

The permissible stress $\sigma_{p e r}$ is determined using the equation (38):

$$
\sigma_{p e r}=\frac{R_{e}}{k}
$$

where $k$ is safety coefficient, $R_{e}$ is yield strength of selected material for crane hook. The selected value of safety coefficient is $k=1.8$. The crane hook RSN 05 P - DIN 15401 with a load capacity of $500 \mathrm{~kg}$ is selected for lifting mechanism of single girder bridge crane (Fig. 7).

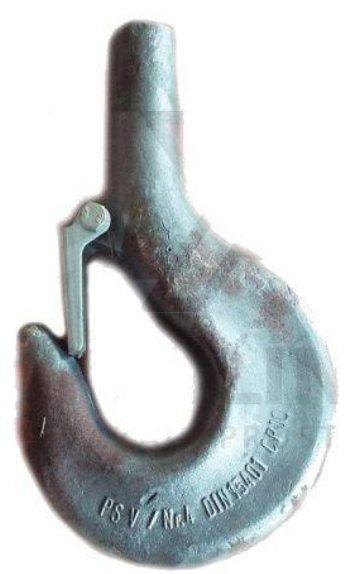

Fig. 7 Selected crane hook RSN 05 P - DIN 15401 (Pavlínek, 2021)

The crane hook is made from material C15 with a yield strength of $300 \mathrm{MPa}$. Subsequently, substituting the values into equation (38), it is possible to calculate the permissible stress $\sigma_{\text {per }}$.

$$
\begin{gathered}
\sigma_{p e r}=\frac{300}{1.8} \\
\sigma_{p e r}=166.67 \mathrm{MPa} .
\end{gathered}
$$

After substituting values into condition (37), it is clear that the used crane hook is satisfying. 
Stresses and other parameters obtained by analytical calculation are summarized in the following Tab. 3 .

Tab. 3 Results obtained by analytical calculation

\begin{tabular}{llrr}
\hline Parameter & Notation & \multicolumn{1}{c}{ Value } & \multicolumn{1}{c}{ Unit } \\
\hline Area of the trapezoid cross-section & $\mathrm{S}$ & 814 & $\mathrm{~mm}^{2}$ \\
Radius of the neutral axis & $\mathrm{R}$ & 35 & $\mathrm{~mm}$ \\
Statical moment of the cross-sectional area & $\mathrm{S}_{\mathrm{y}}$ & 2100.12 & $\mathrm{~mm}^{3}$ \\
Tensile stress & $\sigma_{\mathrm{t}}$ & 6.03 & $\mathrm{MPa}$ \\
Bending moment & $\mathrm{M}_{\mathrm{o}}$ & 159020.1 & $\mathrm{Nmm}$ \\
Bending stress at location A & $\sigma_{\mathrm{oA}}$ & 80.17 & $\mathrm{MPa}$ \\
Bending stress at location B & $\sigma_{\mathrm{oB}}$ & 26.64 & $\mathrm{MPa}$ \\
Total stress at location A & $\sigma_{\mathrm{A}}$ & 86.2 & $\mathrm{MPa}$ \\
Real total stress & $\sigma_{\mathrm{Ar}}$ & 114.93 & $\mathrm{MPa}$ \\
Permissible stress & $\sigma_{\mathrm{per}}$ & 166.67 & $\mathrm{MPa}$ \\
\hline
\end{tabular}

\section{STRENGTH ANALYSIS OF CRANE HOOK USING ANSYS SOFTWARE}

Finite element analysis (FEA) is understood as a simulation of a physical phenomenon using a numerical mathematical technique called the finite element method (FEM). Analysing most of vary phenomena can be done using partial differential equations, but in complex situations where multiple highly variable equations are needed, Finite Element Analysis is the dominant mathematical technique (English, 2019). First, it is necessary to model the crane hook in some CAD software for the strength analysis in Ansys software. Subsequently, it is possible to perform this analysis, from which the results of Von Mises stress, total deformation and safety factor are obtained.

\subsection{D model of the crane hook}

The 3D model of selected crane hook with $500 \mathrm{~kg}$ lifting capacity is designed in working environment of Catia V5 software. This crane hook would be a part of lifting mechanism of the single girder bridge crane with load capacity of $500 \mathrm{~kg}$.

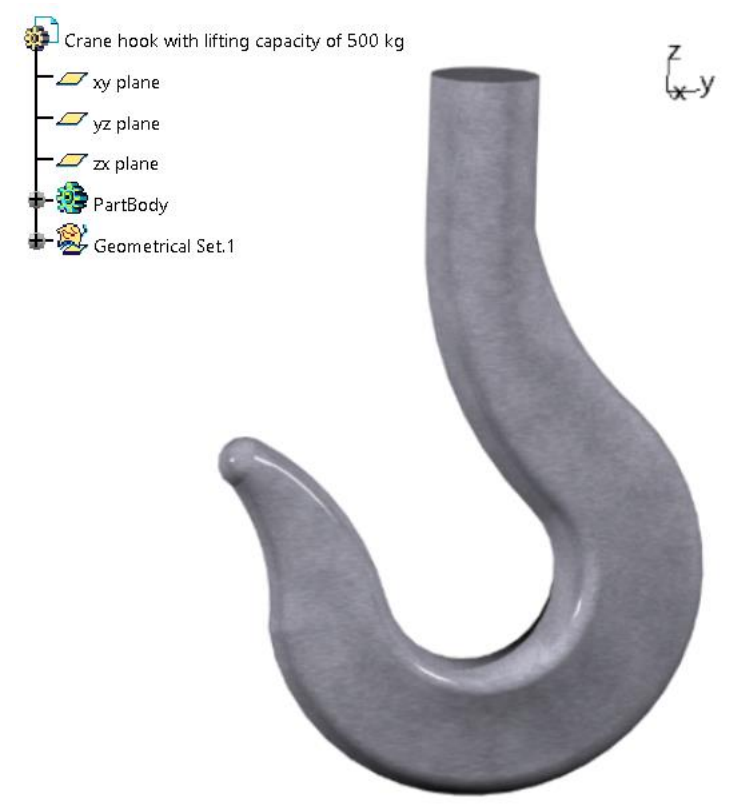

Fig. 8 3D model of the selected crane hook with applied material

Dimensions of the crane hook is used from the Tab. 2. The modelled crane hook (Fig.8) is used for strength analysis in Ansys. The C15 material is applied on the modelled crane hook. 


\subsection{Results from the FEA in Ansys}

The crane hook model saved in stp. format is imported into the Ansys workbench. Subsequently, the static structural analysis of this model in this workbench is performed. The crane hook model is represented as volume object. First, the model needs to be meshed. Meshes are generated by means of FEM by element in quadratic form. Size of each element is $2 \mathrm{~mm}$. Elements are of the quadratic type, thanks to which a better description of the sudden change of shape is possible. A fine meshing is applied on this solid model of the crane hook. The number of elements is 12580 and nodes is 22438 . Fig. 10 shows a created meshed model of the crane hook.

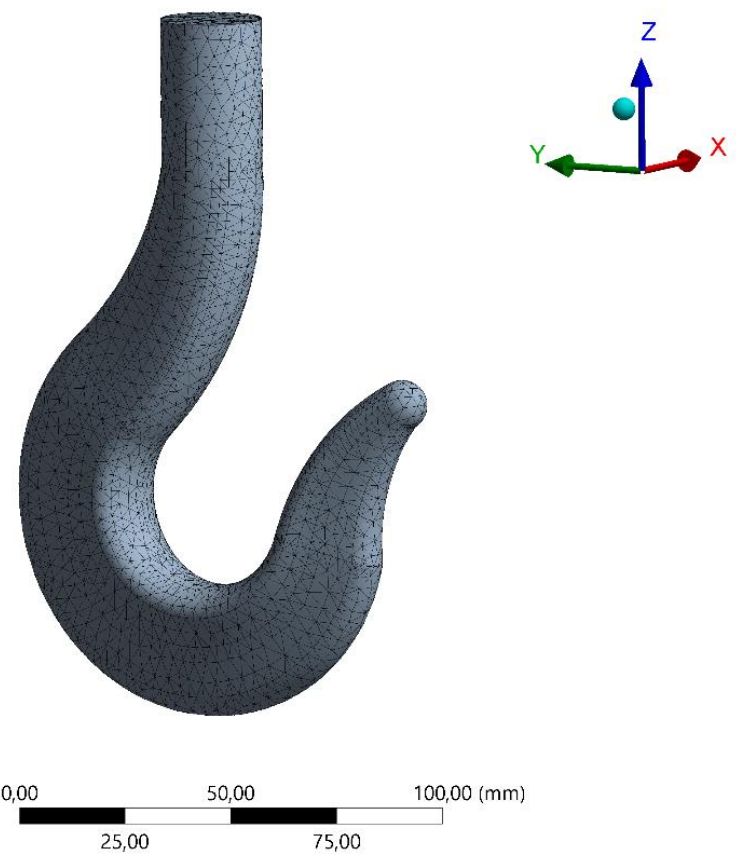

Fig. 9 Crane hook meshing

The crane hook model is fixed at a shank end. The load is applied to the surface created on the inside of the hook rounding i.e., at the lower center of the hook. The load (500 kg/4905 N) acts in downwards and it is evenly decomposed throughout the created surface (Fig. 10).

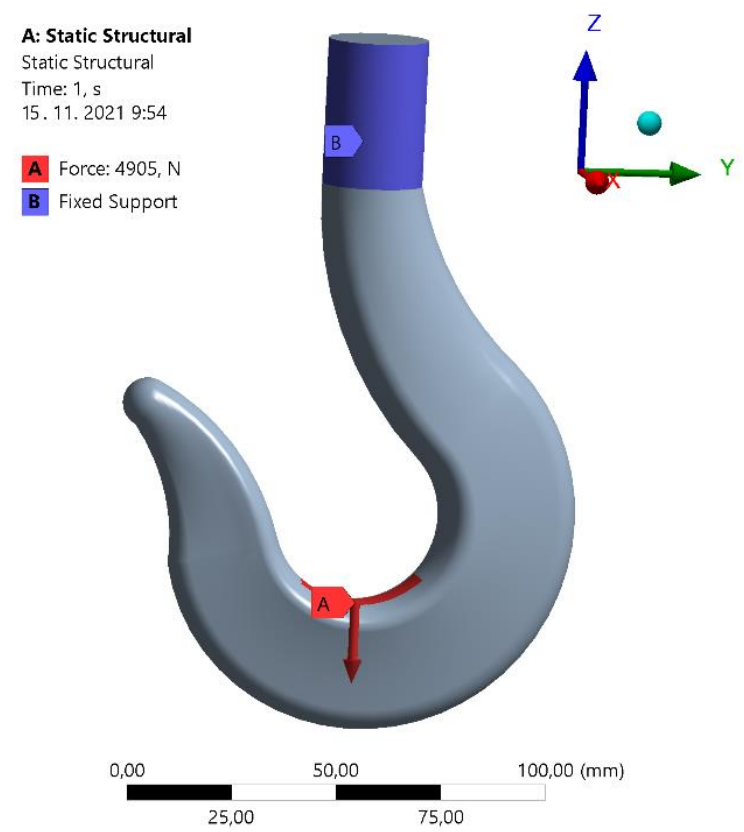

Fig. 10 Boundary conditions applied on the crane hook 
Desired results such as equivalent stress (Fig. 11), total deformation (Fig. 13) and factor of safety (Fig. 14) are analysed.

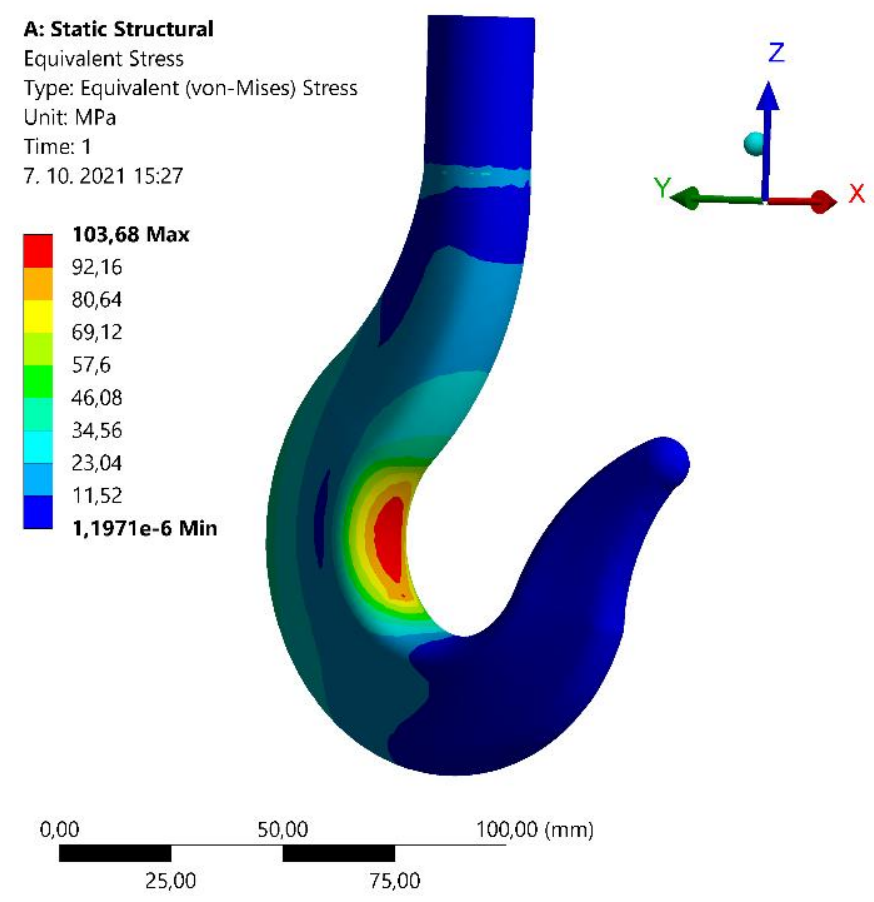

Fig. 11 Stress analysis of the crane hook

The maximum stress (von-Mises) takes the value 103,68 MPa. The most stressed place (red colour) on the crane hook can be seen in Fig. 11. A sectional cut can be made at the point of maximum stress (von-Mises). It is possible to see the stress distribution in this cross-section and maximum value of the von-Mises stress marked by red box (Fig.12), too.
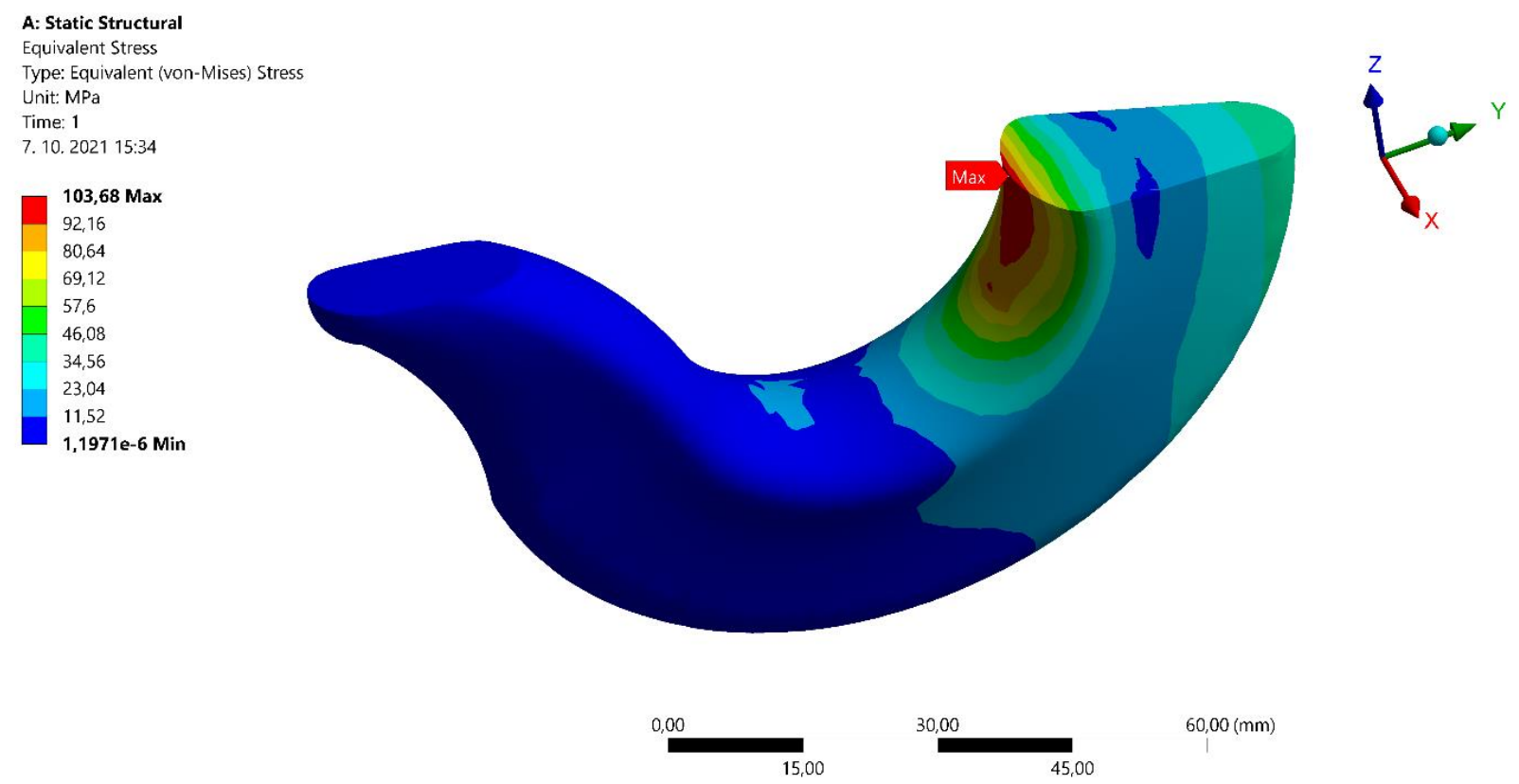

Fig. 12 Stress distribution in cross-section

The value of total deformation received from Ansys is $0.141 \mathrm{~mm}$. 


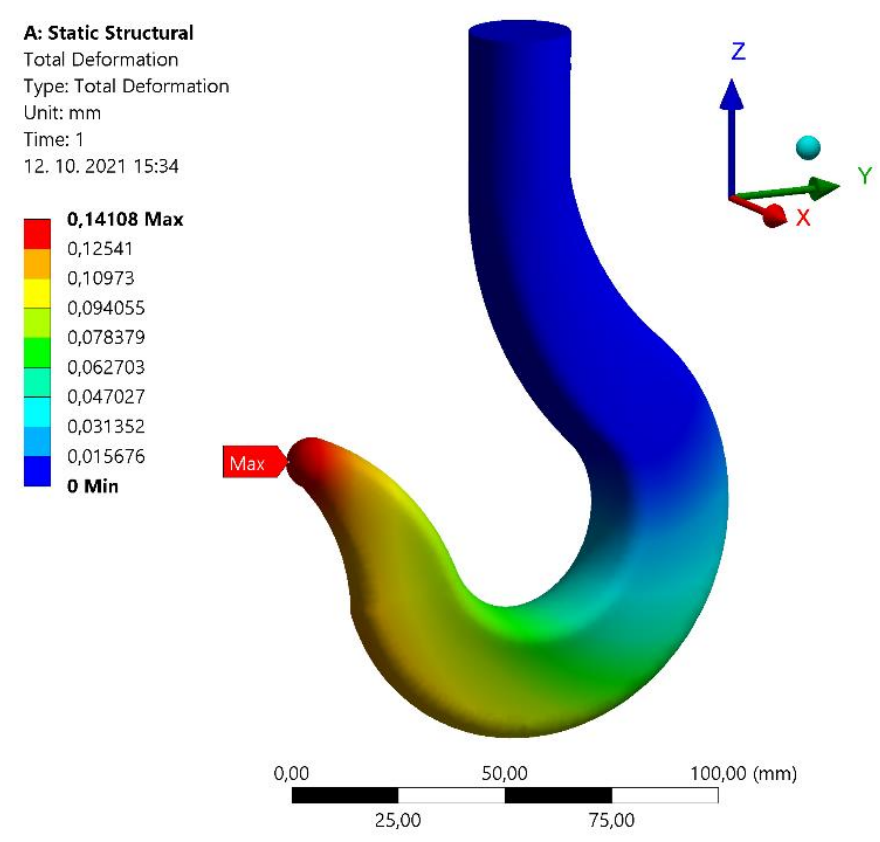

Fig. 13 Deformation analysis of selected crane hook

The value of safety factor received from Ansys is 2.8935 .
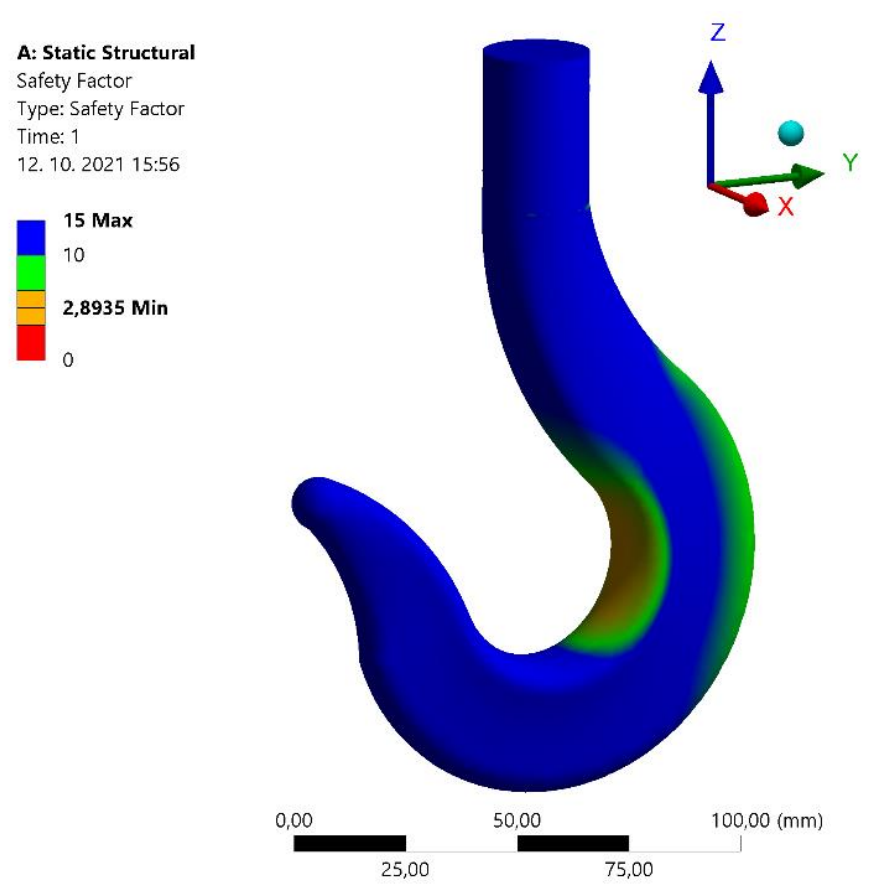

Fig. 14 Factor of safety

The results obtained by FEA analysis using Ansys software are summarized in Tab. 4 .

Tab. 4 Results obtained from Ansys

\begin{tabular}{llll}
\hline Parameter & Notation & Value & Unit \\
\hline Maximum stress (Von-Mises) & $\sigma_{\mathrm{VM}}$ & 103.68 & $\mathrm{MPa}$ \\
Total deformation & $\delta$ & 0.141 & $\mathrm{~mm}$ \\
Factor of safety & $\mathrm{k}_{\mathrm{s}}$ & 2.8935 & - \\
\hline
\end{tabular}

Subsequently, it is possible to compare the total stress determined by the analytical calculation and the maximum stress obtained by FEA analysis in Ansys software. It can be stated from the values given in Tab. 
5 , that the maximum stress obtained by the Ansys software acquires a lower value than the total stress determined by the analytical calculation.

Tab. 5 Comparison of obtained stresses

\begin{tabular}{lll}
\hline Stress & Notation & Value [MPa] \\
\hline Real total stress & $\sigma_{\mathrm{Ar}}$ & 114.93 \\
Maximum stress (Von-Mises) & $\sigma_{\mathrm{VM}}$ & 103.68 \\
\hline
\end{tabular}

\section{CONCLUSIONS}

One of the purposes of this paper was to approach the issue of crane hooks. Hook design principles and materials used in the production of crane hooks were presented. Forged crane hooks are considered to be the most used in practice due to their advantageous properties. The main goal of this paper was the design and strength check of the crane hook for the single girder bridge crane with the load capacity of $500 \mathrm{~kg}$. The crane hook RSN 05 P - DIN 15401 of material C15 was selected. The hook strength check was performed by analytical calculation and by FEA in Ansys software. The value of the total stress of 114.93 MPa was determined by analytical calculation. This value is less than the permissible stress value of 166.67 $\mathrm{MPa}$, so that the selected crane hook is satisfying. FEA analysis in Ansys software gave a maximum stress of $103.68 \mathrm{MPa}$, which is less than the permissible stress as well as the calculated total stress. Thus, also based on the result from the FEA analysis, the crane hook is satisfying. In addition, the value of the total deformation of the hook and the value of the safety factor was received by FEA analysis. The maximum value of the total deformation is $0.141 \mathrm{~mm}$ and the value of the safety factor is 2.89 . This crane hook, with the designed dimensions and its shape presented by means of the 3D model created in Catia, represents one of the possible hook design solutions for the mentioned bridge crane. The design and strength control of the crane hook together create a precondition for its possible production and subsequent use for the lifting mechanism of the single girder bridge crane with the load capacity of $500 \mathrm{~kg}$.

\section{Acknowledgements}

This research was supported by the Cultural and Educational Grant Agency of the Ministry of Education of the Slovak Republic in the project No. KEGA 023ŽU-4/2020: Development of advanced virtual models for studying and investigation of transport means operation characteristics.

\section{References}

Allbiz (C) 2021. Catalogue of construction machinery components and spare parts. Available at: https://ua.all.biz/en/hooks-lamellar-g-p-to-320-0tn-hooks-crane-g-p-0-5-g1257745 [Accessed: 2021, October 2].

Bigoš, P., Kul'ka, J., Kopas, M., Mantič, M. 2012. Theory and design of lifting and transport equipment (In Slovak). Košice: Technical University of Košice, 356 p., ISBN 978-80-553-1187-6.

Blatnický, M. 2015. Transport and handling equipment, solved exercises (In Slovak). Žilina: University of Zilina, 120 p., ISBN 978-80-554-1039-5.

CMCO (c) 2018. Why use a Ramshorn hook. Available at:

https://www.cmworks.com/Public/64781/Ramshorn\%20Form\%20B HR. [Accessed: 2021, November 30].

Cvekl, Z., Zavadil, J. 1960. Lifting machines and conveyors (In Czech). 2. edition. Prague: STNL - publishing house of technical literature, $133 \mathrm{p}$.

Deutsches Institut für Normung. 1982. Lifting hooks for lifting appliances; Single hooks; Unmachined parts. DIN 15401. Berlin: DIN. 
Deutsches Institut für Normung. 1982. Lifting hooks for lifting appliances; Ramshorn hooks; Unmachined parts. DIN 15402. Berlin: DIN.

Dr. Kitaw, D. 2001. Pulleys, Sprockets, Drums and Load Handling Attachements. Material Handling Equipment, pp. 76 - 80.

English, T. 2019. What Is Finite Element Analysis and How Does It Work. Interesting engineering [Online]. Available at: https://interestingengineering.com/what-is-finite-element-analysis-and-how-does-it-work [Accessed: 2021, October 8].

Gopichand, A., Lakshmi, R. V. S., Maheshkrishna, B. 2013. Optimization of design parameter for crane hook using taguchi method. International Journal of Innovative Research in Science, Engineering and Technology, 02(12), pp. 7780-7784, ISSN 2319-8753.

Kardile, S. V., Khan, R. E., Dhakane, D. P., Gore, P. A., Mahajan, D. B. 2017. Design and Analysis of Crane Hook with Different Materials. International Research Journal of Engineering and Technology (IRJET), 04(03), pp. 1919 - 1922, e-ISSN 2395-0056.

Lakshmana Moorthy, S.K., Prakash, B. 2020. Design and Analysis of Crane Hooks of Different Cross Sections Made of Hardened-Tempered Alloy Steel AISI 6150 and AISI 4140. International Research Journal of Engineering and Technology (IRJET), 09(05), pp. 435-439, ISSN 2278-0181.

Pavlínek.sk. (C) 2021. Hooks for chain slings. Available at:

https://www.pavlinek.sk/shs-el-hak-so-zavitom/ [Accessed: 2021, October 1].

Pavlínek.sk. (C) 2021. Catalogue of crane hooks. Available at:

https://www.pavlinek.sk/jednoduchy-zeriavovy-hak-rsn-din-15401-vykovok-bez-zavitu-s-poistkoutrieda-p/ [Accessed: 2021, October 5].

Remta, F., Kupka, L., Dražan, F. 1974. Cranes (In Czech). 2. edition. Prague: STNL - publishing house of technical literature, $648 \mathrm{p}$.

Sudhakar, N., Florence, M., Maisuria, M., Patel, D. 2017. Finite element analysis of crane hook. In National Conference on Progress, Research and Innovation in Mechanical Engineering. Surat, March 2017. Gurajat, India: Sarvajanik College of Engineering \& Technology, pp. 1-4.

Slovak Office of Standards, Metrology and Testing. 1989. Design of steel structures for cranes. Calculation according to limit states. STN 27 0103. Bratislava: STN.

Slovak Office of Standards, Metrology and Testing. 1963. Cranes and hoists. Forged hooks with shank. STN 27 1908. Bratislava: STN.

Tigabey, S. 2018. Optimization and Fatigue Analysis of Crane Hook Using Finite Element Method. Addis Abbaba: Addis Abbaba University, School of mechanical and industrial engineering.

Vítů, Š. 2019. Crane hooks, design and calculation (In Czech). Brno: VÚT Brno. 